\title{
Neuropathic Pain and Spasticity Response to Traditional Acupuncture after Spinal Cord Injury
}

Gabriella Fizzotti ${ }^{1 *}$, Maurizio Piccinini ${ }^{2}$ Giovani Fassina ${ }^{3}$, and Livio Tronconi ${ }^{3}$.

${ }^{1}$ Spinal Unit, ICS Maugeri SPA SB, Institute of Pavia, IRCCS, Pavia, Italy.

${ }^{2}$ Rehabilitation Unit, Cittadella Sociale Medical Centre. Pieve del Cairo, Pavia, Italy.

${ }^{3}$ IRCCS Mondino Foundation Pavia, University of Pavia, Pavia, Italy.

*Corresponding Author: Gabriella Fizzotti, Spinal Unit, ICS Maugeri SPA SB, Institute of Pavia, IRCCS, Pavia, Italy.

Received date: May 07, 2021; Accepted date: October 01, 2021; Published date: October 08, 2021

Citation: Gabriella Fizzotti, Maurizio Piccinini, Giovani Fassina, Livio Tronconi (2021). Neuropathic Pain and Spasticity Response to Traditional Acupuncture after Spinal Cord Injury. J. Neuroscience and Neurological Surgery. 9(5); DOI:10.31579/2578-8868/211

Copyrights: ( 2021 Gabriella Fizzotti, This is an open-access article distributed under the terms of The Creative Commons Attribution License, which permits unrestricted use, distribution, and reproduction in any medium, provided the original author and source are credited.

\begin{abstract}
Introduction: One of the most relevant disabilities is caused by spinal cord injury (SCI). Typical causes of spinal cord damage are trauma, disease, or congenital disorders. Tetraplegia is a paralysis results in the partial or total loss of use of all limbs and torso; paraplegia is similar but does not affect the arms. Pain and spasticity are common sequelae of SCI [1]. Both pain and spasticity can have a late onset and develop slowly over time after SCI, and once developed, they often become chronic.

In this paper we have provided to assess the effectiveness of acupuncture for treating SCI sequelae and summarize the potential mechanisms of acupuncture therapy.

Method: We considered 30 patients with diagnosis of tetra or paraplegia after SCI complicated by neuropathic pain and spasticity. Neurologist trained in medical acupuncture conducted the therapeutic treatments. A specific set of acupuncture points was used in all sessions. Participants were treated for 8 sessions of acupuncture over 4 week's period. Pain and spasticity were evaluated with Numeric Raiting Scale (VAS) (2) and the Modified Ashworth Scale [3] at the beginning of the first, the fourth an eighth treatment session.

Results: 28 patients (93\%) showed improvement in pain intensity and spasticity after two weeks of acupuncture treatment. The therapeutic effect continued until the eighth week of treatment. However, 15 patients $(53,5 \%)$ reported an increase in spasticity and pain 2 months after acupuncture sessions.

Conclusions: Acupuncture sessions using defined acupoint set reduced pain intentensity and spasticity in patients with SCI.

Keywords: acupuncture; pain spasticity; spinal cord injury
\end{abstract}

\section{Introduction}

According to the World Health Organization the term 'spinal cord injury' refers to damage to the spinal cord resulting from trauma (e.g. a car crash) or from disease or degeneration (e.g. cancer). [4] Traumatic spinal cord injuries most commonly occur as a result of motor vehicle and motor-bike accidents, followed by falls. Sport, in particular, water-based activities and work-related injuries are also common, with a further small but increasing contribution from a gun, knife or war-related injury. [5,6] (Figure-1)

Common Causes of Spinal Cord Injury (2016) 


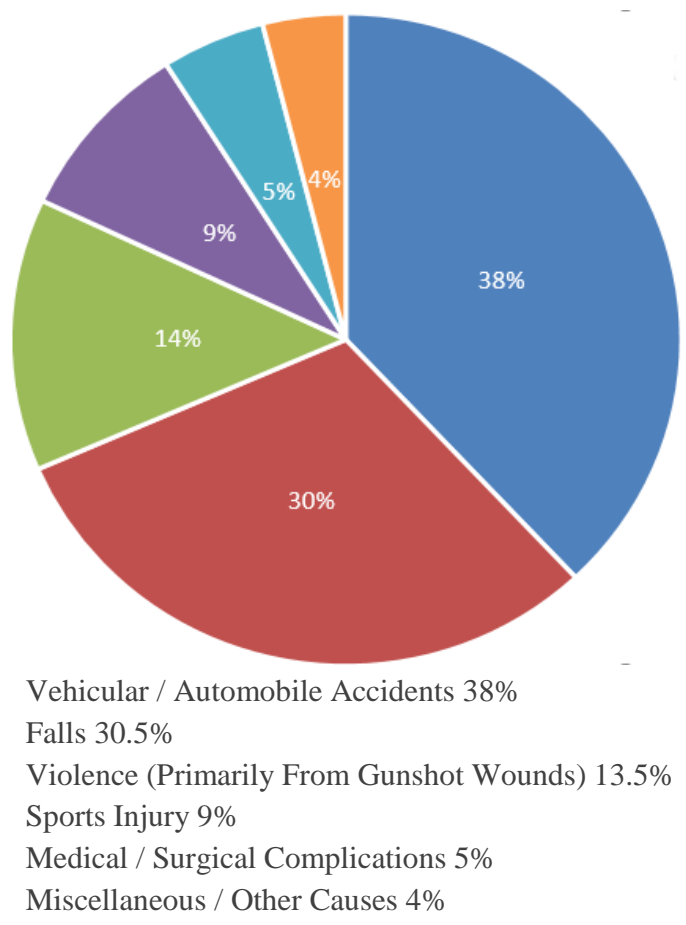

Figure 1: Causes of traumatic spinal cord injury. Source: The National Spinal Cord Injury Statistical Center

Tetraplegia, also known as quadriplegia, is a paralysis caused by illness or injury that results in the partial or total loss of use of all limbs and torso; paraplegia is similar but does not affect the arms. The loss is usually sensory and motor, which means that both sensation and control are lost [7]. The rehabilitation process following a spinal cord injury normally begins in the acute care setting. The clinical outcomes of SCI depend on the severity and location of the lesion and may include partial or complete loss of sensory and/or motor function below the level of injury. A primary goal of rehabilitation is to restore, to the greatest possible extent, the physical functioning of an individual after illness or injury.

Knowledge of possible complications during the acute phase is important because they may be life-threatening and/or may lead to prolonged rehabilitation.

The range of conditions following SCI can be categorized into neurological consequences and resulted from the injury itself, following interruption and decentralization of central nervous system and may be regarded as sequel to the injury. [8] Example are neurogenic pain or spasticity; the latter being part of the upper neurone syndrome. Neuropathic pain is present in $50-60 \%$ and spasticity in about $70 \%$ of individuals living with a SCI. (9-10) Central neuropathic pain shares many features with spasticity and has even been termed 'sensory spasticity'. [11] Both pain and spasticity can have a late onset and develop slowly over time after SCI, and once developed, they often become chronic. Neuropathic pain is defined as "pain caused by a lesion or disease of the somatosensory nervous system. [12]

Neuropathic pain following SCI includes at- and below-level SCI neuropathic pain, where at-level pain may consist of both peripheral and central neuropathic pain, while below-level pain is a central neuropathic pain condition. [13] Studies have found that patients with spinal cord injury who suffer from pain have less life satisfaction than do patients in whom pain is well controlled; this may also affect the patients' general outlook on life $[14,15]$.

Spasticity has been defined as 'a disordered sensorimotor control resulting from an upper motor neuron lesion, presenting as intermittent or sustained involuntary activation of muscles', and this broad definition of spasticity is adopted in the spinal cord injury musculoskeletal data set. [16]

Neurological consequences may interfere with the start of active rehabilitation, can slow down the achievement of outcomes during rehabilitation and sometimes lead to re-hospitalization

Life expectancies for patients with spinal cord injury continues to increase but are still below the general population. Patients aged 20 years at the time they sustain these injuries have a life expectancy of approximately 35.7 years (patients with high tetraplegia [C1-C4]), 40 years (patients with low tetraplegia [C5-C8]), or 45.2 years (patients with paraplegia) [17]. Individuals aged 60 years at the time of injury have a life expectancy of approximately 7.7 years (patients with high tetraplegia), 9.9 years (patients with low tetraplegia), and 12.8 years (patients with paraplegia).

Originally the leading cause of death in patients with spinal cord injury who survived their initial injury was renal failure, but, currently, the leading causes of death are pneumonia, pulmonary embolism, or septicemia. Heart disease, [18-19] subsequent trauma, suicide, and alcohol-related deaths are also major causes of death in these patients [2021]. In persons with spinal cord injury, the suicide rate is higher among individuals who are younger than 25 years.

There are many treatments for functional recovery from injury and the related complications that result from SCI; these include surgery [22], prescription drugs [23], behavioral therapy [24], physical therapy [25], and supportive treatment [26]. There are also a variety of treatments used for the secondary complications of SCI, such as intermittent catheterization for bladder dysfunction, analgesics for pain, and others [27]. Treatment options for spasticity are effective and include oral medication (baclofen, tizanidine), intrathecal baclofen, and rarely, surgical rhizotomy or myelotomy.

These treatments tend to be administered over long periods of time, and because of the potential complications of treatment, there has been an increased interest in alternative medical treatments, including acupuncture and other related therapies (moxibustion and acupressure) [28]. 
Acupuncture is an important part of Traditional Chinese Medicine, which has been used for more than 4000 years to prevent and treat a variety of diseases. Even though the technique was first developed in China, it is now practiced by thousands of clinicians worldwide and has become one of the most frequently used complementary medicine therapies among SCI patients. Many researchers have found acupuncture to be effective in a large number of patients for not only nociceptive condition but also for neuropathic pain $[29,30,31,32,33]$. The effect of acupuncture on spasticity has been proven by several studies, Zhang et al. concluded that the nanometer acupoint mounting method through defined acupoints can significantly alleviate myospasms complicated by spinal injury, compared with the non-acupuncture group [34]. Another Chinese study also proved that acupuncture combined with Western medicine could improve SCI-induced spasticity after spinal cord injury, compared with treatment with Western medicine alone [35]. It is important to advance knowledge on people with SCI and strengthen the evidence base for prevention, support and care of people with SCI. In this paper we have provided to assess the effectiveness of acupuncture for treating post-SCI complications and summarize the potential mechanisms of acupuncture therapy for SCI.
Acupuncture has been administered to 30 SCI patients, aged between 16 and 80, treated at the Spinal Unit of Maugeri IRCCS Foundation. Patients were recruited consecutively from January 2019 to December 2019. Spinal cord injuries were classified as complete and incomplete by the American Spinal Injury Association (ASIA) classification [36]. The ASIA scale grades patients based on their functional impairment from A to $\mathrm{E}$, where A represents the greatest impairment and $\mathrm{E}$ represents the normal condition. Neurologist trained in medical acupuncture conducted the therapeutic treatments. During the procedure, a hair-thin needle is inserted into the skin at distinct acupoints (Table1). Participants were treated for 8 sessions of acupuncture over a 4 week period. After insertion, needles were left in place for 30 minutes and were not manually or electrically stimulated. Needles were inserted to a depth of 15 to 30 $\mathrm{mm}$. A specific set of acupuncture points was used with all participants: 5TB Waiguan, 41 GB Linqi. 20 GB Fengchi, 34 GB Yinglingquan, 4 GI Hegu, 3 LV Taichong, 36 ST Zusanli. We have focussed on inserting needles into fixed anatomical locations (table 1). At the beginning of the first, fourth an eighth treatment session, each participant was asked to describe the quality and location of pain and spasticity: an operator evaluated VAS [2] and Modified Ashworth [3] scale respectively.

\section{Material and Method}

\begin{tabular}{|c|c|}
\hline Acupuncture Poin & Location \\
\hline GB 41 Zulinqi & $\begin{array}{l}\text { Posterior to the 4th metatarsophalangeal joint, in the depression lateral to the } \\
\text { tendon of } \mathrm{m} \text {. extensor digiti minimi of the foot. }\end{array}$ \\
\hline TH 5 Waiguan & $\begin{array}{l}\text { On the dorsal aspect of the forearm, on the line connecting SJ } 4 \text { and the tip of } \\
\text { the elbow, } 2 \text { cun above the transverse crease of the wrist between the ulna } \\
\text { and radius. }\end{array}$ \\
\hline GB 20 FengChi & $\begin{array}{l}\text { At the top of the sternocleidomastoid muscle which runs from the back of the } \\
\text { head down to the front of the shoulders at the clavicle. }\end{array}$ \\
\hline GB 34 YangLingC & Quan In the depression anterior and inferior to the small head of the fibula. \\
\hline GI 4 Hegu & $\begin{array}{l}\text { On the dorsum of the hand, between the first and second metacarpal bones, at } \\
\text { the midpoint of the second metacarpal bone and close to its radial border. }\end{array}$ \\
\hline LV 3 Taichong & $\begin{array}{l}\text { On the dorsum of the foot in a depression distal to the junctions of the } 1 \text { st and } \\
\text { 2nd metatarsal bones. }\end{array}$ \\
\hline ST 36 Zusanli & $\begin{array}{l}\text { On the finger breadth lateral to the lower border of the tuberositas tibiae } 3 \text { cun } \\
\text { below the knee joint }\end{array}$ \\
\hline
\end{tabular}

Table 1: Acupoints

\section{Results}

At the time of the acupuncture treatment, all patients were hospitalised. Thirty patients presented a traumatic spinal cord injury. Median age was 58 years in men and 69 years in women. Patients in acute phase of disease were 12. Patients distribution among ASIA categories was well balanced (14 patients were ASIA A or B). Acupuncture may be effective in treating a subgroup of patients who have pain and spasticity after traumaic SCI. Sixty-five percent of the present study sample reported moderate to significant pain relief immediately after the course of 16 treatments and $25 \%$ of the sample continued to report pain relief at 2-month follow-up.

Our data provide preliminary evidence indicating that the subgroup reporting spasticity relief after acupuncture. Forty-six percent of the present study sample reported moderate to significant spasticity relief immediately after the course of 16 treatments and 5\% of the sample continued to report spasticity relief at 2-month follow-up. Patients with incomplete injuries appear to do better than those with complete ones.VAS scale evidenced a reduced pain intensity in $64,4 \%$ patients with acute SCI and $30 \%$ with chronic SCI. Fifty - seven percent of acute SCI patients reported spasticity relief and $30 \%$ of chronic SCI reported the same result. Spasticity responds better in acute incomplete SCI compared to chronic; the percentage change is equal to $31,5 \%$..

In term of safety no serious adverse events related acupuncture were reported in anyone of the 30 patients. 


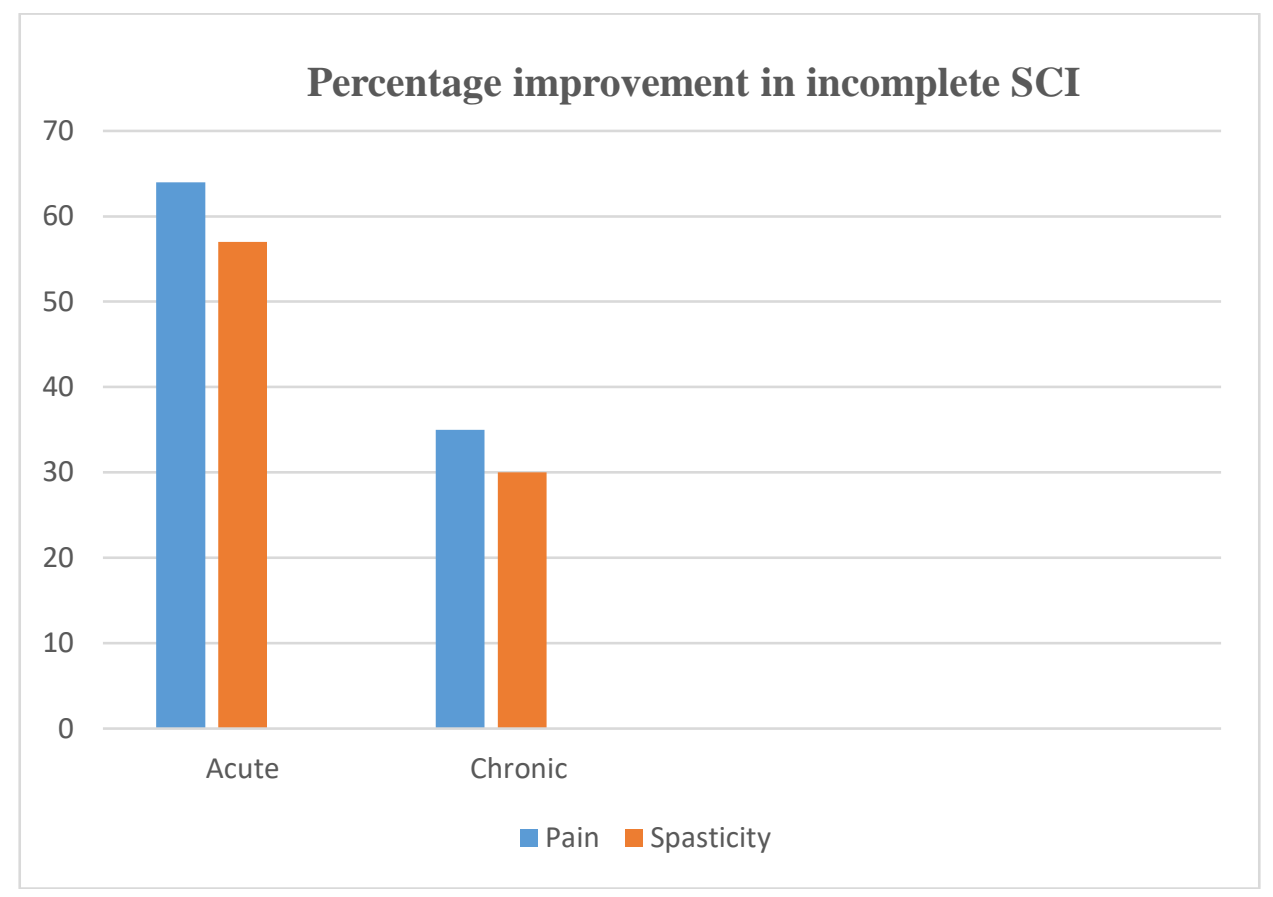

Figure 2: Pain and Spasticity improvement after acupuncture treatment in incomplete acute and chronic spinal cord injury

\section{Discussion}

Our data provide preliminary evidence indicating that the subgroup reporting neuropatic pain and spasticity relief after acupuncture. Patients with incomplete injuries appear to do better than those with complete ones. This result might explain because the pathway to the central nervous system is still intact. Acute SCI evidenced better results than chronic SCI patients.

Despite the fact that response to acupuncture was not effective in the long term it is still encouraging that $65 \%$ of partecipants reported moderate to significant pain and $46 \%$ to spasticity relief immediately after treatment.

Several theories about the mechanism of acupuncture may explain why neuropatic pain relief after acupuncture. One suggests that the insertion of acupuncture needles stimulates the release of endorphins. [37] Given that central pain is more refractory to conventional treatment [38], this finding suggests that acupuncture may provide a viable treatment alternative for some individuals with this kind of pain.

The mechanism of the effect of acupuncture on spasticity is still unclear. It is widely accepted that acupuncture can reduce pain. Acupuncture therapy could break the pain-spasm-pain cycle and relax muscles by controlling pain [39]. The threshold of pain receptor is increased after location stimulation [40-41]. However, the mechanism cannot explain all causes because spasticity is not always painful and the link between spasticity and pain is not clearly established. SCI can trigger neuroplasticity that potentially promotes recovery from the injury but it also may have deleterious consequences. Neuropathic pain and spasticity are multifactorial and complex consequences of maladaptive neuronal plasticity after SCI. [1]. Following an initial impact after spinal cord injury (SCI), there is a cascade of downstream events termed 'secondary injury', which culminate in progressive degenerative events in the spinal cord. These secondary injury mechanisms include, but are not limited to, ischemia, inflammation, free radical-induced cell death, glutamate excitotoxicity, cytoskeletal degradation and induction of extrinsic and intrinsic apoptotic pathways [42] Different aspect of pain and spasticity, and injury characteristics may reflect different underlying mechanisms. [1] Decrease oxidative stress, inhibition of inflammation and neuronal apoptosis, regulation of the expression and activity of endogenous biological mediators, and increase regenerative stem cell production are the possible mechanism of acupuncture therapy for SCI. McCouch proposed another aetiological mechanism: the distruption in the balance between excitatory and inhibitory inputs to motoneurons observed during spasticity. Enhanced excitability of motoneurons and interneurons and axonal sprouting are the most likely mechanisms involved in spasticity [43]. Management of spasticity can include physical exercise, medication, and electrostimulation [44]. Evidence from experiments in humans and animal models of spasticity demonstrated that alterations in the excitability of numerous excitatory and inhibitory spinal pathways occur after SCI. The pathogenesis of spasticity resulting from SCI is multifactorial and extend beyond the stretch reflex. It also depends on the type, site, and duration of injury. The alteration in excitability of various inhibitory pathways has historically been studied the most, with less focus until recently on the alterations in excitability of motoneurons and interneurons themselves. This latter alteration appear to play critical role in the manifestation of spasticity after SCI [45]. The enhancement in excitability of motoneurons is most likely involved in pathophysiology of spasticity following SCI. Acupuncture therapy may regulate the activity of spinal motor neurons by decreasing the hyperexcitability of gamma and alfa motor neuron and/or increasing the inhibition of interneurons. Fink et al. [46] and Lee et al. [47] found that after the first acupuncture treatment, $\mathrm{H} / \mathrm{M}$ ratios decreased immediately as compared with controls. The improvement in $\mathrm{H} / \mathrm{M}$ ratio may be associated with decreased excitability of alfa motor neurons. Yu et al. [48] found that acupuncture on the antagonist muscle of the spastic muscle could prolong the mean $\mathrm{H}$ reflex recovery time, which may be caused by the increased inhibition of interneurons. The use of complementary and alternative medicine (CAM) to relieve pain for the patients with SCI has been assessed in several studies. As in our survey, CAM was used as a supplementary rather than an exclusive treatment. In Pannek's study $73 \%$ of the SCI patients reported the use of CAM for chronic pain [49]. Acupuncture was the most frequent technique ( $28 \%$ of the participants), with a pain relief that lasted for weeks in $19 \%$ of the users [50]. A meta-analysis showed positive results for the use of acupuncture for pain in SCI [51]. The percentage of SCI patients seeking help for their chronic medical conditions by CAM is 
high. Therefore, a comprehensive care of SCI patients should not be limited to the various forms of conventional treatments, but should include CAM procedures as well.

\section{Conclusion}

Acupuncture seems to be a potential therapeutic intervention for SCI pain and spasticity. Neurological complication of SCI may interfere with the start of active rehabilitation, can slow down the achievement of outcomes during rehabilitation and sometimes lead to re-hospitalization. The possibility to use acupuncture sessions complementary to the individual rehabilitation program (PRI) in SCI can be useful to perform activities of daily living without shooting and burning pain, spasms and increased muscle tone. There are several limitations to the described study. These findings must be replicated in a longer term study that has a larger sample, including a nonacupuncture control group. Further researches are needed in this direction to develop valid and reliable instruments to assess the health status in people with SCI.

\section{Funding}

This research received no specific grant from any finding agency in the public, commercial or not for profit sectors.

\section{Declaration of conflicting interests}

The authors declared no potential conflicts of interest with respect to the research authorship and/or publication of this article.

\section{Patient consent}

Obtained.

The study was approved by the Ethics Committee of our Centre and all patients provided written informed consent before study treatment.

\section{Provenance and peer review}

Not commissioned; externally peer reviewed.

\section{References}

1 Finnerup NB. Neuropatic pain and spasticity: intricate consequences of spinal cord injury. Spinal Cord Injury (2017) 55, 1046-1050).

2 Melzack R, KatzJ, Pain measurement in person in pain. In Melzack R, Wall PD, editors. Texbook of pain. New York: Churchill Livingstone; 1999. P xii, 1588.

3 Meseguer-Henarejos AB, Sánchez-Meca J, López-Pina JA, Carles-Hernández R. Inter- and intra-rater reliability of the Modified Ashworth Scale: a systematic review and metaanalysis. Eur J Phys Rehabil Med. 2018 Aug;54(4):576-590.

4 World Health Organization, International Spinal Cord Society. International Perspectives on Spinal Cord Injury. World Health Organization; 2013.

5 Singh A, Tetreault L, Kalsi-Ryan S, Nouri A, Fehlings MG. Global Prevalence and Incidence of Traumatic Spinal Cord Injury. Clinical Epidemiology. 2014;6:309.

6 Furlan JC, Sakakibara BM, Miller WC, Krassioukov AV. Global Incidence and Prevalence of Traumatic Spinal Cord Injury. Canadian Journal of Neurological Sciences. 2013 Jul;40(4):45664.

$7 \quad$ Kirshblum S; Campagnolo D; Delisa J (2001). Spinal Cord Medicine. Lippincott Williams \& Wilkins. pages 108-122.

8 Siddall PJ, McClelland JM, Rutkowski SB, Cousins MJ. A longitudinal study of the prevalence and characteristics of pain in the first 5 years following spinal cord injury. Pain 2003; 103 : $249-257$.

9 Burchiel KJ, Hisu FP. Pain and spasticity after spinal cord injury: mechanism and treatment. Spine 2001: 26: S146-S160.
10 Burke D, Fullen BM, Stokes D, Lennon O. Neuropathic pain prevalence following spinal cord injury: A systematic review and meta-analysis. Eur J Pain 2017; 21: 29 -44.

11 Sjolund BH. Pain and rehabilitation after spinal cord injury: the case of sensory spasticity? Brain Res Brain Res Rev 2002; 40: $250-256$.

12 Jensen TS, Baron R, Haanpaa M, Kalso E, Loeser JD, Rice AS et al. A new definition of neuropathic pain. Pain 2011; 152: 2204-2205.

13 Brown A, Weaver LC. The dark side of neuroplasticity. Exp Neurol 2012; 235: 133-141.

14 Budh CN, Osteråker AL. Life satisfaction in individuals with a spinal cord injury and pain. Clin Rehabil. 2007 Jan. 21(1):89-96.

15 Widerström-Noga E, Biering-Sørensen F, Bryce T, Cardenas DD, Finnerup NB, Jensen MP, et al. The international spinal cord injury pain basic data set. Spinal Cord. 2008 Dec. 46(12):818823.

16 Pandyan AD, Gregoric M, Barnes MP, Wood D, Van WF, Burridge $\mathrm{J}$ et al. Spasticity: clinical perceptions, neurological realities and meaningful measurement. Disabil Rehabil 2005; $27: 2-6$.

17 National Spinal Cord Injury Statistical Center (NSCIS). Spinal cord injury facts and figures at a glance. February 2011.

18 Morse LR, Stolzmann K, Nguyen HP, Jain NB, Zayac C, Gagnon $\mathrm{DR}$, et al. Association between mobility mode and C-reactive protein levels in men with chronic spinal cord injury. Arch Phys Med Rehabil. 2008 Apr. 89(4):726-731.

19 Furlan JC, Fehlings MG. Cardiovascular complications after acute spinal cord injury: pathophysiology, diagnosis, and management. Neurosurg Focus. 2008. 25(5):4-13.

20 Turner AP, Bombardier CH, Rimmele CT. A typology of alcohol use patterns among persons with recent traumatic brain injury or spinal cord injury: implications for treatment matching. Arch Phys Med Rehabil. 2003 Mar. 84(3):358-364.

21 Frisbie JH, Tun CG. Drinking and spinal cord injury. $J$ Am Paraplegia Soc. 1984 Oct. 7(4):71-73.

22 Bregman BS, Coumans JV, Dai HN, et al. Transplants and neurotrophic factors increase regeneration and recovery of function after spinal cord injury. Progress in Brain Research. 2002; 137:257-273.

23 Attal N, Mazaltarine G, Perrouin-Verbe B, Albert T. Chronic neuropathic pain management in spinal cord injury patients. What is the efficacy of pharmacological treatments with a general mode of administration? (oral, transdermal, intravenous) Annals of Physical and Rehabilitation Medicine. 2009;52(2):124-141

24 Norrbrink Budh C, Kowalski J, Lundeberg T. A comprehensive pain management programme comprising educational, cognitive and behavioural interventions for neuropathic pain following spinal cord injury. Journal of Rehabilitation Medicine. 2006;38(3):172-180.

25 Silverman SR, Schertz LA, Yuen HK, Lowman JD, Bickel CS. Systematic review of the methodological quality and outcome measures utilized in exercise interventions for adults with spinal cord injury. Spinal Cord. 2012;10(50):718-727.

26 Huston T, Gassaway J, Wilson C, Gordons S, Koval J, Schwebe A. The SCIRehab project: treatment time spent in SCI rehabilitation. Psychology treatment time during inpatient spinal cord injury rehabilitation. Journal of Spinal Cord Medicine. 2011;34(2):196-204.

27 Finnerup NB, Jensen TS. Spinal cord injury pain-mechanisms and treatment. European Journal of Neurology. 2004;11(2):7382. 
28 Dorsher PT, McIntosh PM. Acupuncture's effects in treating the sequelae of acute and chronic spinal cord injuries: a review of allopathic and traditional Chinese medicine literature. Evidencebased Complementary and Alternative Medicine. 2011;2011428108

29 Biering-Sorensen F, Burns AS, Curt A, Harvey LA, Jane MM, Nance PW et al. International spinal cord injury musculoskeletal basic data set. Spinal Cord 2012; 50: 797-802.

30 T.A. Dyson-Hudson, P. Kadar, M. LaFountaine, R. Emmons, S.C. Kirshblum, D. Tulsky, et al.Acupuncture for chronic shoulder pain in persons with spinal cord injury: a small-scale clinical trial. Arch Phys Med Rehabil, 88 (10) (2007), pp. 12761283

31 C. Norrbrink, T. Lundeberg. Acupuncture and massage therapy for neuropathic pain following spinal cord injury: an exploratory study, Acupunct Med, 29 (2) (2011), pp. 108-115

32 Y.S. Gwak, H.Y. Kim, B.H. Lee, C.H. Yang. Combined approaches for the relief of spinal cord injury-induced neuropathic pain. Complement Ther Med, 25 (2016), pp. 27-33

33 Sangeetha Nayak, PhD, Samuel C. Shiflett, PhD, Nancy E. Schoenberger, PhD, Sandra Agostinelli, MA, Steven Kirshblum, MD, Allison Averill, MD, Ann C. Cotter, MD. Is acupuncture effective in treating chronic pain after spinal cord injury. Archives of Physical Medicine and Rehabilitation Volume 82, Issue 11, November 2001, Pages 1578-1586.

34 Zhang SJ, Si T, Li Z. Clinical observation on nanometer acupoint mounting method for alleviation of myospasm complicated by spinal injury. Zhongguo Zhen Jiu 2008;28(11):849-851.

35 J-g Dong, Qui Y-y Integrative medicine efficacy of rehabilitation therapy on patients with spinal cord injury spasm relief. China J Mod Med 2012: 23: 023

36 Kirshblum SC, Waring W, Biering-Sorensen F et al. Reference for the 2011 revision of the International Standards for Neurological Classification of Spinal Cord Injury. J Spinal Cord Med. 2011 Nov;34(6):547-554

37 Stux G, omeranz B. Basics of acupuncture. New York Springer. 1989 p 6-12.

38 Roth E. Controlling pain in spinal cord injury. Rehabil Manage 1991: Feb-Marc; 63-67.

39 Shin BC, Lim HJ, Lee MS. Effectiveness of combined acupuncture therapy and conventional treatment on shoulder range of motion and motor power in stroke patients with hemiplegic shoulder subluxation: a pilot study. Int J Neurosci 2007; 117:519-523

40 Lee JD, Chon JS, Jeong HK, et al. The cerebrovascular response to traditional acupuncture after stroke. Neuroradiology 2003;45:780-784.

41 Rabinstein AA, Shulman LM. Acupuncture in clinical neurology. Neurologist 2003;9:137-48.

42 Park E, Velumian AA, Fehlings MG. The Role of Excitotoxicity in Secondary Mechanisms of Spinal Cord Injury: A Review with an Emphasis on the Implications for White Matter Degeneration

43 Ebasioury SW, Maroz D, Bakr MM, Mushahwar VK. Management of spasticity after spinal cord injury: current techiniques and future directions. Neurirehabil Neural Repair 2010; 24(1): 23-33.

44 Bethoux F. Spasticity Management after stroke. Phys Med Rehabil Clin N Am2015: 26(4):625-639.

45 SM. Elbasiouny, d Moroz, MM Bakr, VK Mushahwar. Management of spasticity after spinal cord injury: current technique and future directions. Neurorheab Neural Repair 2010 Jannuary; 24 (1): 23-33.

46 Fink M, Rollnik JD, Bijak M, et al. Needle acupuncture in chronic poststroke leg spasticity. Arch Phys Med Rehabil 2004;85:667-672.

47 Lee S, Yun J, Son J, et al. The effect of electroacupuncture on upper-extremity spasticity of stroke patients. J Intern Korean Med 2007;28:492-501.

$48 \mathrm{Yu} \mathrm{YH}$, Wang HC, Wang ZJ. The effect of acupuncture on spinal motor neuron excitability in stroke patients. Zhonghua Yi Xue Za Zhi. Chinese medica ljournal; Free China ed. 1995;56:258263.

49 Pannek J, Pannek- Rademacker S, Wollner J. Use of complementary and alternative medicine in persons with spinal cord injury in Switzerland: a survey study. Spinal Cord (2015) 53, 569-572.

50 Cardenas DD, Jensen MP. Treatments for chronic pain in persons with spinal cord injury: a survey study. J Spinal Cord Med 2006; 29: 109-117.

51 Heo I, Shin BC, Kim YD, Hwang EH, Han CW, Heo KH. Acupuncture for spinal cord injury and its complications: a systematic review and meta-analysis of randomized controlled trials. Evid Based Complement Alternat Med 2013; 2013: 364216.

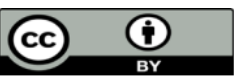

This work is licensed under Creative Commons Attribution 4.0 License

To Submit Your Article Click Here: Submit Manuscript

DOI: $10.31579 / 2578-8868 / 211$
Ready to submit your research? Choose Auctores and benefit from:

$>$ fast, convenient online submission

$>$ rigorous peer review by experienced research in your field

$>$ rapid publication on acceptance

$>$ authors retain copyrights

$>$ unique DOI for all articles

$>$ immediate, unrestricted online access

At Auctores, research is always in progress.

Learn more https://auctoresonline.org/journals/neuroscience-andneurological-surgery 